\title{
1. Establishing the art of contextualizing management ideas and panaceas as a research field Anders Örtenblad
}

$[\mathrm{M}]$ anagement ideas are not monoliths and there is no reason why they should be (Mamman 2002, p. 380)

This book is about the kind of 'packaged' thoughts on management that become popular through being 'defined as having an unlimited reach and application' (Christensen and Lægreid 2003, p.6) and, thus, often are presented as if they are widely (Perkmann and Spicer 2008) or even universally (Huczynski 1993 [1996]; Røvik 2002; Sorge and Van Witteloostuijn 2004) applicable. These will in the present book go under the notion of 'management ideas and (management) panaceas'. Some of the management ideas and panaceas taken up in the book are:

- achieving competitive excellence (ACE);

- competitive intelligence (CI);

- corporate social responsibility (CSR);

- corporatization;

- Japanese management;

- knowledge management;

- organizational culture;

- pay secrecy;

- $\quad$ social cognitive theory (SCT);

- strategic human resource management (SHRM);

- the learning organization;

- total quality management (TQM);

- transformational leadership.

However, the book is not primarily about any one particular concept listed above, but instead on such management ideas/panaceas in general, and specifically on how to determine their relevance and adapt them to fit organizations that are about to start using them or that are already using them. Not all of the terms in the above list are known as 'management ideas', therefore the notion used here is 'management ideas and panaceas'. 
The image that is given of these management ideas and panaceas in management books and at many business schools is often one-sided or polarized at best. They are mostly presented as quick-fix panaceas (in its positive sense) that bring all kinds of advantages to the organizations that adopt them, such as profitability, competitiveness and survival (Huczynski 1993 [1996]; Kieser 1997; Røvik 2002). Occasionally, the management ideas and panaceas are severely criticized. Both of these discourses tend to be one-sided; the supportive discourse rarely or never takes up any downsides that the management ideas and panaceas might have, and the skeptical discourse rarely or never mentions any gains that might occur from the use of the management ideas and panaceas. For instance, the idea of the learning organization tends to be described either as 'utopian sunshine' or as 'Foucauldian gloom' (Driver 2002), that is, either in terms of a one-sided recommendation to adopt the idea as is or, alternatively and much less often, a one-sided recommendation to all organizations to reject the idea. While most organizational actors as well as people in general probably only meet the praising presentations, this polarization is still unfortunate in that it tends to give rise to an 'either/or' approach, where management ideas and panaceas are either good or bad, and should either be fully adopted or fully rejected.

Unlike the major part of the previous literature, this book is neither uncritically praising the management ideas and panaceas, nor is it arguing that all management ideas and panaceas are rubbish. Only partly in agreement with the many researchers who tend to show skepticism towards management ideas and panaceas (Nicolai and Röbken 2005, pp.416-17), this book's keystone is that management ideas and panaceas of course should be criticized but also may add at least some value - through being used instrumentally - to the organizations in which they are used and, thus, that there are both pros and cons to any specific management idea/panacea (Abrahamson 1991; Kieser 1997; Collins 2000; Gibson and Tesone 2001). The book suggests that the relevance of any particular management idea or panacea for any individual organization or for organizations in a 'generalized context' (such as a particular industry, sector, national culture or religion) must be critically examined, and the management idea/panacea might need to go through adaptation before it becomes fully relevant for the particular organization or generalized context. Hence, rather than suggesting that management ideas and panaceas should be adopted outright (implying that the management ideas/panaceas remain unchanged while the organizations adopting them go through changes), or abandoned outright (implying that the management ideas/panaceas as well as the organizations remain unchanged), this book suggests that adoption and abandonment are two possible 
outcomes of a process whereby the relevance of a particular management idea/panacea for an organization (or organizations in a generalized context) is explored, and where adaptation (implying that the management ideas/panaceas are changed and that the organizations adopting them either also go through changes or remain unchanged) is another possible outcome.

The book is meant to contribute to existing knowledge and wisdom about the art of examining and advising on the relevance of management ideas and panaceas for organizations in various situations and contexts. The overall purpose is to establish the area as a research area in its own right. On a more concrete level, the book aims to develop knowledge on how more wisely to examine the relevance of any particular management idea/panacea for individual organizations as well as for organizations in generalized contexts. The book also aims at developing knowledge on how to adapt any particular management idea or panacea if it shows during the examination of it that it is not fully relevant in its original form for the individual organization or for organizations in the generalized context.

In the remainder of this chapter the research question is specified through the elaboration of some basic assumptions underlying the book, through justification in some more depth of the need for the book, through relating the book to previous contextualization research, and through defining some central concepts appearing in the book. At the end of the chapter, the remainder of the book is outlined.

\section{BASIC ASSUMPTIONS}

The book rests upon some important basic assumptions. First, it focuses on instrumental use (Pelz 1978) of management ideas and panaceas, rather than on symbolic use (Pelz 1978). Accordingly, the use of management ideas and panaceas for gaining legitimacy is a down-prioritized subject in the book. ${ }^{1}$ When discussing how more wisely to determine the relevance of management ideas and panaceas, it is the instrumental relevance that is at stake. In case symbolic use instead had been emphasized, then the best recommendation for a particular organization could have been that it should pretend that it had adopted the management idea or panacea at stake in practice, and thereby appear in a favorable light, but should avoid actually adopting it in practice, that is, decouple talk and action (cf. Meyer and Rowan 1977). Instead, focusing on instrumental use means that there is often (but not always) a need for clarity regarding what any particular management idea or panacea means, a reasoning that is based on the presumption that management ideas' and panaceas' 'clear 
structure permits swift and precise action' (Fink 2003, p.47). The focus on instrumental use also implies that there often may be a need for guidelines for actual adoption of the management idea or panacea at stake.

Second, even if many tend to 'jump on the bandwagon' and use the same management ideas and concepts as others do, the book rests upon the assumption that actors are capable of making decisions that to at least a certain degree are rational and, thus, at any rate hesitate before jumping on the bandwagon. As Watson (1994, p.903) argues, managers are not 'completely unreflective fad-mongers' (see also Mazza and Strandgaard Pedersen, Chapter 19 in this volume). Thus, the kind of translation that is focused on in this book is the one that Røvik (1998) terms 'rationally calculated translation', rather than the 'unintended translation' (Røvik 1998). The book is about helping various groups of actors make, if not fully rational decisions (which may not be possible see Abrahamson Löfström, Chapter 17 in this volume), at least wiser decisions when it comes to handling management ideas and panaceas.

Third, the book takes a 'critical-pragmatic approach' (see Örtenblad and Koris 2014) towards management ideas and panaceas; it is neither taken for granted that the management ideas and panaceas at stake are relevant, nor that they are irrelevant. In contrast, the book suggests that there is a need to develop knowledge on how more wisely to critically examine management ideas/panaceas and to figure out which parts or aspects of them can reasonably function successfully in certain situations, rather than to accept or discard them outright, although full acceptance or full rejection may be the recommendation after the examination has been conducted.

Fourth, the book rests upon a contingency perspective (see, for example, Fiedler 1978; Mintzberg 1981, 1983): whether or not a particular management idea or panacea is (fully) relevant for any specific organization has to be investigated in each single case and is contingent upon certain factors that characterize the particular organization and its situation (factors that, for instance, have to do with that organization's size, which industry/ sector and national culture it exists in, and so on).

\section{A NEED FOR INCREASED KNOWLEDGE}

There are mainly three reasons as to why increased knowledge on the contextualization and adaptation of management ideas and panaceas is needed. First, based on an effectiveness perspective, doing the same as others may be far from the best way to compete (Czarniawska and Joerges 1996, p.16; Thomas, Chapter 4 in this volume). Thus, rather 
than making efforts to standardize management ideas/panaceas and the process of adopting them, which would lead to homogenization among the organizations adopting the particular idea/panacea, there is reason to develop knowledge regarding how these can be adapted to fit various organizations, and through adopting these context-adapted models organizations can differentiate themselves.

Secondly, there is a risk that management ideas and panaceas that appear attractive but that are fully or partly irrelevant are adopted (cf. Abrahamson 1991). Organizational actors tend to jump on the bandwagon' in a herd-like way (Sorge and Van Witteloostuijn 2004), something which cannot be recommended (for example, Ryan and Hurley 2004), at least not when the instrumental use of management ideas and panaceas is at stake. Previous studies of management ideas and panaceas have shown that while these on an abstract level may appear to be easily graspable and attractive, they are often vague and/or ambiguous if being examined in more depth (for example, Kieser 1997; Benders and van Veen 2001; Mamman 2002; Benders and Verlaar 2003; Giroux 2006). Even if vagueness and ambiguity definitely can contribute to creativity, for instance in the sense that vague management ideas can be more easily adapted to different contexts (for example, Røvik 1996, p. 142; Alvarez 1998, p. 43; Scarbrough and Swan 2001, p. 8), there is a risk that essential and even vital elements of the particular idea/panacea are not adopted or that elements that would be fatal for the organization are adopted (cf., for example, Eccles and Nohria 1992, p.94). Thus, there is reason to help organizational actors avoid 'maladaptive responses' such as dissociation or evangelicism (Whittle, Chapter 10 in this volume), to the continuous stream of 'new' management ideas and panaceas.

Thirdly, and also stemming from the vagueness and ambiguity that management ideas and panaceas come with (as was taken up above), with a purpose of seduction particularly managers but potentially also other actors may present different versions of a particular management idea/panacea at different occasions and for different groups of actors, internal or external to the organization, in order to deceive the various groups (cf. Davis 1986; Astley and Zammuto 1992; Kelemen 2000; see also Benders and van Veen 2001, p. 38). For example, through presenting different versions of the management idea/panacea at stake, managers can simultaneously appear in a favorable light and avoid costly changes of their business or changes that may cause decreased profit. It may seem awkward that seductive use of management ideas and panaceas is brought up here, considering that this book focuses on the instrumental use of management ideas and panaceas. But the different versions of the 'same' management idea/panacea that are presented for different groups, and 
thus decoupled (Meyer and Rowan 1977), must not necessarily consist of talk decoupled from talk or talk decoupled from practice - it may also be that practice is decoupled from practice.

This suggests that it may not be reasonable to involve only organizational actors in the process of developing knowledge on how more wisely to contextualize management ideas and panaceas, but also other groups of actors, such as researchers and students. In fact, the reasons outlined above for why there is a need for increased knowledge in this area, seem to give researchers quite a few reasons to 'intervene' (Abrahamson 1996; Abrahamson and Eisenman 2001; see also Birkinshaw et al. 2008) and engage in 'researcher-assisted contextualization' (cf. Örtenblad 2013, p.9) of management ideas and panaceas. However, involving researchers by no means guarantees an unbiased or even a nuanced treatment of management ideas and panaceas. As Sturdy (2004, p. 155) has argued, there is a tendency within studies of the adoption of management ideas that researchers 'either idealize or marginalize managerial rationality'. Researchers are also often less familiar with the context than the organizational actors are. Moreover, it has been suggested that even academics are sensitive to what is fashionable and, thus, have fashions themselves (McKinley 1996; Örtenblad 1999; Andersson 2008; Starbuck 2009; Bort and Kieser 2011), something which is also discussed in this book by several contributors (for example, Parker, Chapter 23 in this volume; Whittle, Chapter 10 in this volume). For these reasons one cannot expect that researchers automatically would act in a purely rational and unbiased way when contextualizing management ideas and panaceas or when in other ways helping to determine the relevance of management ideas and panaceas for various organizations.

\section{PREVIOUS CONTEXTUALIZATION STUDIES}

There is not much previous research that closely connects to the issues dealt with in the present book. Nevertheless, there are a few areas that are relevant for the book. The main difference between these areas, which are presented in the following, and this book is that the latter more explicitly has a normative orientation. However, in one case the previous literature shows evidence of being too normative.

First, during the last few decades increased attention has been given to the context - primarily in terms of national culture - when generating and testing theory on the basis of empirical research studies, in areas such as organizational behavior (see, for example, Johns 2001), organizational research (see, for example, Rousseau and Fried 2001), organizational 
science (see, for example, Boyacigiller and Adler 1991), international management research (see, for example, Tsui 2007; Whetten 2009), and leadership development (see, for example, Bruning and Tung 2013). Hofstede (1996) takes the importance of the context one step further when suggesting that organizational theories are culture-bound in that the individual researcher conducting the research is culture-bound. This research tradition has an empirical focus in the sense that the empirical data decide whether or not and, if so, to what extent a particular theory is relevant in a certain context. The kind of study within this research tradition that relates the most to the present book is probably the more normatively oriented study that tests the relevance of theories developed in one context in another context, such as Fey and Denison's (2003) study in which they found that a model of organizational culture developed in the US can be used in the Russian context to predict differences in effectiveness. Just like the contingency approach that was taken up above, this research tradition's major input to the present book is the call for contextualized theories (which for the present book means contextualized management ideas and panaceas).

Second, there is a research tradition that sometimes comes under the notion of the 'translation perspective' and is based on the theory of sociology of translation (see, for example, Callon 1986; Latour 1986, 1987) as well as on the works that brought this theory into the studies of the spread of management ideas and panaceas (Czarniawska and Joerges 1996; Czarniawska and Sevón 1996). Such studies have a descriptive approach and follow the spread of management ideas/panaceas in time and space and study how their meanings (often) change as they are being interpreted and reinterpreted by various actors (for example, Doorewaard and van Bijsterveld 2001; Frenkel 2005; Lervik et al. 2005; Boxenbaum 2006; Morris and Lancaster 2006; Stensaker 2007; Risberg and Søderberg 2008; Heiskanen et al. 2009; Wæraas and Sataøen 2014; see also Eccles and Nohria 1992; Fiss et al. 2012, even if they do not explicitly use the translation perspective). The majority of this kind of study has focused on organizational actors' translation, but occasionally scholars have studied researchers' translation of management ideas and panaceas (Bartunek and Spreitzer 2006; Örtenblad 2007). The studies in this research tradition are descriptive, in contrast to the normative, ex ante considerations dealt with in this book. Such a descriptive focus has helped to allocate knowledge on how translation of management ideas actually takes place. In addition to the organization's problems and needs in relation to its context, less rational factors - such as organizational actors' values, beliefs, interests and experiences (Love and Cebon 2008; see also Whittle, Chapter 10 in this volume) - are offered as explanations as to how certain management 
ideas and panaceas are interpreted and why their meanings change. Thus, the translation perspective per se can give helpful insights when it comes to how management ideas/panaceas in various ways can be contextualized, but offers less help when it comes to recommending how management ideas and panaceas should be contextualized.

Third, there is already a research tradition aiming at putting certain management ideas and panaceas into context. Examples include the adaptation of supply chain management to make it fit Tanzanian small and medium sized enterprises (SMEs) (Hamisi 2011); the adaptation of the learning organization to make it fit schools (Kinder 2002), elderly care organizations (Abrahamson Löfström 2013), Islamic organizations (Ahmad 2013), and higher educational institutions (HEIs) (Watkins 2005; Örtenblad and Koris 2014); the adaptation of knowledge management to make it fit Chinese organizations (Mitra and Ruan 2014), Mexican organizations (Delgado-Hernández 2014), the army (McDowell et al. 2014), indigenous organizations (Lwoga et al. 2014), and energy sector organizations (Edwards 2014); and the adaptation of corporate social responsibility (CSR) to make it fit the shipping industry (Lekakou et al. forthcoming) and organizations in developing countries (Jamali and Karam forthcoming). Possibly, these works could be regarded as having been conducted in response to more or less explicit calls for context-adapted models of various management ideas and panaceas from, for instance, Sorge and Van Witteloostuijn (2004) who suggested that management ideas may make tangible contributions, but only after they have been adapted; and Mamman (2002), who argued that modification of management ideas/ panaceas is inevitable, taking into account the characteristics of the idea in question and the organization's internal and external contingencies, and advocated the need for versions of management ideas accommodating the diversity of organizations. However, even though the studies listed above have critically examined the relevance of the management idea/panacea at stake for organizations in certain generalized contexts, there is reason to believe that many other studies where a particular management idea or panacea is put into context treat the management idea/panacea as an ideal. Outright adoption is recommended and the studies tend to discuss how the implementation of the management idea or panacea in its original form can best be performed, rather than examining the relevance of it. This is at least what was found in a review of works on HEIs as learning organizations (Örtenblad and Koris 2014; see also Örtenblad, Chapter 11 in this volume; Örtenblad et al., Chapter 12 in this volume). Thus, there still seems to be reason to explore how studies of the relevance of certain management ideas and panaceas for individual organizations or organizations in certain generalized contexts could be performed more wisely and, thus, 
develop 'relevance-testing and adaptation competence', to paraphrase Røvik (1998) and his concept of 'translation competence'.

\section{DEFINITIONS OF SOME CENTRAL CONCEPTS}

Some general definitions of a few central concepts may help readers to get an understanding of the spirit of the book. The definitions taken up here are to be seen as tentative and general suggestions for how the concepts may be defined. The terminology in this book has not been harmonized between chapters. The individual contributors have been given space and freedom to use whichever concepts they prefer and, in case they use the same concepts that are defined here, to use different definitions of them (at least slightly different).

The first concept to be defined is indeed central in the book:

Context This concept has been given many different meanings (see and compare, for example, Johns 2001; Bamberger 2008; Blackman 2013). Johns (2006, p. 386) defines context as 'situational opportunities and constraints that affect the occurrence and meaning of organizational behavior as well as functional relationships between variables'. The concept of 'generalized context' is here suggested to signify the particular features that characterize a particular context, generally speaking. It may, for instance, be a particular industry, sector, national culture or religion that is generalized and the reasoning, thus, concerns all organizations that share the general context, such as all HEIs, all organizations in the private sector, all organizations in Pakistan, or all Buddhist organizations. A 'contingency approach' is, by Sorge and Van Witteloostuijn (2004, p. 1206), defined as 'reasoning that considers practice to be relative to a specific situation at hand. The epitome of contingency reasoning is the judicious refinement of situational relativity.' A 'contingency model' is here suggested to signify a model containing recommendations for how to practice a certain management idea or panacea in relation to the generalized contexts, such as recommending that organizations in the public sector should avoid adopting a certain aspect of the idea of the learning organization while organizations in the private sector are recommended to adopt it.

Secondly, definitions of some concepts on the 'objects' that this book is about are suggested below, which in the book title and consistently throughout this introductory chapter are termed 'management ideas and panaceas', but that come under other notions even within this book. 
Management idea This is defined by Bort (Chapter 3 in this volume) as 'a broader discourse about how "good" management appears at a particular point in time'. 'Fashionable management idea' is here suggested to signify those management ideas that become really popular. Another term denoting popular management ideas is 'management fashions'.

Management panacea This term is here suggested to signify management ideas that are presented and/or regarded as if the practice of these were capable of curing all kinds of problems in any situation or context for any organization. In Lillrank's words, it is a management method that confesses to no constraints (Lillrank, Chapter 2 in this volume; see also Bort, Chapter 3 in this volume). This 'cure-all' signifier is often included in the definition of concepts such as 'management idea', 'fashionable management idea' and 'management fashion' as well. The reason why the present book makes a distinction between, and takes up both 'management ideas and panaceas' is that at least a few of the management concepts taken up in the book are hardly known as 'management ideas'. Zawadski (Chapter 20 in this volume) handles this by using the term 'panacea-ideas' to signify those management ideas that clearly have 'cure-all' characteristics.

Management practice When a management idea or panacea is implemented in practice, it becomes a management practice (Bort, Chapter 3 in this volume). However, it needs to be mentioned that there are also those who do not make any such clear distinction between the terms 'management idea' (as non-implemented thoughts) and 'management practice' (as implemented thoughts) (see, for example, Zeitz et al. 1999; Ansari et al., Chapter 16 in this volume). Thus, there are those who consistently use the term 'management idea', whether or not it has been implemented, and there are those who consistently use the term 'management practice', whether or not it has been implemented.

Best practice A concept that is defined by Thomas (Chapter 4 in this volume) as 'involving a crystallization of practice into a coherent and prescriptive discourse that can then be exported into new contexts, with the expectation of positive results'.

In the literature within the area, many other concepts are used, all defined more or less similarly to one or more of the above concepts. Examples of such concepts are management fads, administrative innovations, administrative rhetoric, organization ideals, management concepts, management knowledge, management recipes, management innovations, management techniques, management models, management tools, man- 
agement hypes, and so on. These concepts will not, however, be further elaborated on here (but see Bort, Chapter 3 in this volume, for more thoughts and discussion on various concepts).

Thirdly, a few of the concepts that deal with the processes that the 'objects' (see above) go through, and which in the book title were indicated through the sub-title, 'adaptation and context' (that is, contextualization), are tentatively defined.

Relevance-testing This term is suggested to signify the examination of a management idea or panacea in order to determine to what degree it is relevant for any specific organization or organizations in a particular generalized context.

Adaptation This term is suggested to signify the modification of a management idea or panacea so that it better fits any particular organization or organizations in a generalized context. Other terms used more or less synonymously with 'adaptation' include 'contextualization', 'recontextualization' (see Thomas, Chapter 4 in this volume), 'customization', and 'appropriation'. Contextualization is by Rousseau and Fried (2001, p. 1) defined as the 'linking [of] observations to a set of relevant facts, events, or points of view that make possible research and theory that form part of a larger whole'. The suggested definition of 'contextualization' for the present book is putting the management idea or panacea into context in the sense of determining the relevance of and making it fit a particular organization or organizations in a particular generalized context. This means that the term 'contextualization' covers both relevance-testing and adaptation.

Translation This concept is a little bit different from the above '-ation' concepts, in that it rests on the particular theory of sociology of translation (see, for example, Callon 1986; Latour 1986, 1987), implying that management ideas and panaceas do not travel as such but through continuously being interpreted and reinterpreted. For this reason, management ideas and panaceas generally undergo modifications (that is, given a more or less different meaning) when being spread, but it may occasionally also happen that the content is left more or less intact as the idea/panacea spreads in time and space (that is, it may be reinterpreted similarly to how it was first being interpreted). But it must also be noted that there are those who consider all 'translation' to imply 'modification' of the translated item (for example, Lervik et al. 2005).

Types of adaptation of ideas The following terms signify different ways that management ideas and panaceas may be adapted or modified. 
Management ideas and panaceas may go through 'adding', meaning that some elements are added to the management idea or panacea; 'subtraction', indicating that some elements are removed from the management idea or panacea; or 'alteration', which means that the management idea or panacea is radically changed (Røvik 2011; see also Latour 1986, p. 267; Røvik 1998; Mamman 2002; Gond and Boxenbaum 2013). The term 'copying' is not included here, even if it is a form of 'translation' according to Røvik (2011), since it is a term signifying that the management idea or panacea is reinterpreted but that its meaning remains unchanged.

Adoption In contrast to those who use the concept of adoption for the process in which a management idea or panacea merely is introduced to the organization (for example, Zeitz et al. 1999), adoption is here suggested to be used synonymously with 'implementation' and, thus, to signify the process of putting the management idea or panacea into practice. Further, in contrast to those who claim that adoption implies full replication of the management idea or panacea at stake (for example, Lervik et al. 2005), adoption may have been preceded by adaptation of the idea or panacea. 'Outright adoption' is suggested to denote those occasions when the management idea or panacea does not go through any relevance-testing before being adopted, while 'full adoption' is suggested to signify situations when the management idea or panacea is considered, on the basis of a critical examination, not to be in any need of adaptation before adoption of it.

\section{SPECIFIED RESEARCH QUESTION}

The main theme of the book can now be summarized and the research question can be specified. The book discusses how researchers can intervene in the processes of relevance-testing and adaptation of particular management ideas and panaceas to make them fit certain organizations. Since there are reasons to involve several actor groups, the book discusses also how organizational actors themselves can more wisely determine the relevance of any particular management idea or panacea for their organization, and how education can be arranged so that students get opportunities to learn how to contextualize management ideas and panaceas. When offering recommendations for wiser contextualization processes, attention is not only given to how to better fulfill values such as efficiency and effectiveness, but also other values are taken into account.

The book takes a 'critical-pragmatic' approach. Instead of viewing management ideas and panaceas as ideals and recommending their outright adoption, or as frauds that must be rejected, this book aims to increase 
knowledge on how the relevance of any particular management idea or panacea, to be used instrumentally, can be examined, either for any individual organization or for organizations in any particular generalized context. The book also aims at increasing knowledge on how management ideas and panaceas to be used instrumentally can best be adapted to fit either any individual organization or organizations in generalized contexts. That is, the book aims to help actors balance between adopting, abandoning and adapting, ${ }^{2}$ not only in an effective way but also in a sound or wise way. Thus, this book aims at developing 'relevance-testing and adaptation competence' among various groups of actors, such as researchers, organizational actors, lecturers and students.

In relation to many of the previous studies relating to contextualization within the management and organization area, this book has a more normative orientation and an ex ante approach. This normativity has three levels: (1) the book recommends how various groups of actors (including researchers) can more wisely conduct contextualization of management ideas and panaceas; (2) contextualizing, per se, means normative recommendations, in terms of suggesting how a certain management idea or panacea has to be defined in order to fit a particular organization or organizations in a particular generalized context; and (3) the 'objects' that are dealt with in this book, that is, management ideas and panaceas, are in themselves normative. In contrast to many previous studies in which management ideas and panaceas are put into context, the present book has a 'critical-pragmatic' approach, rather than treating management ideas and panaceas as ideals or frauds, which is common in previous literature.

\section{THE REMAINDER OF THE BOOK}

The remainder of the book is structured according to the following:

\section{Part I: Background and Introduction}

Part I offers a theoretical and conceptual background to the book, and thus the three other chapters in Part I complement the present chapter by explaining some central concepts and suggesting theoretical perspectives. In Chapter 2, 'The anatomy of managerial panaceas: ontology, epistemology and technology', Paul Lillrank helps us better to understand the concept of panacea and what a panacea may be, and answers questions such as how to spot a panacea and how to dissect a panacea. In Chapter 3, Suleika Bort defines some of the many concepts that are used parallel to the concept of 'management idea', a chapter entitled 'Turning a 
management innovation into a management panacea: management ideas, concepts, fashions, practices and theoretical concepts'. As a basis for the normatively oriented theorizing in this book, Pete Thomas suggests, in Chapter 4, 'Putting panaceas into practice . . . or not: translating discourse into social practice in complex and contested terrains', a discourse-based and process-oriented frame of reference for understanding how context influences the translation of discourse into other moments of practice and how the discursive aspects of the panacea become translated into, for example, beliefs, actions and relationships.

\section{Part II: Panaceas in Need of Contextualization}

Part II of the book argues for the need to contextualize panaceas. A few examples of management panaceas and their (limited) universality are examined. These chapters serve as a background to the rest of the book, in that they emphasize the importance of taking the context into account when advising on the relevance of certain management ideas and panaceas for any particular organization. The section deals not only with the traditional kind of 'management idea panaceas'; as varied things as an administration policy, a nation and a psychological theory are treated as panaceas in the four chapters.

In Chapter 5, 'Panacea or Pandora's box? The role of fairness perceptions and interpersonal competitiveness in determining how pay secrecy affects individual task performance', Elena Belogolovsky and Peter Bamberger discuss the universality of an administration policy - pay secrecy - which is often regarded as a panacea, while the authors argue that in fact it is not. In Chapter 6, 'The curious case of Japanese management: a nation as a panacea', Paul Lillrank not only deals with the universality of the panaceas of Japan and Japanese management, but also discusses how they became hype and reflects on his own role in the appearance of these panaceas. More specifically, panaceas such as the quality control circle and lean production are discussed.

In Chapter 7, 'The importance of context when applying social cognitive theory in organizations', John McCormick, Seyyed Babak Alavi and José Hanham deal with a psychological theory that has been applied relatively often in work contexts - social cognitive theory (SCT). According to the authors, SCT may be viewed as a coherent and extensive set of theories that effectively explains and predicts human motivation and behavior. McCormick, Alavi and Hanham deal with four sub-theories of SCT, namely triadic reciprocal determinism, self-efficacy, collective efficacy and proxy efficacy, and relate each of these to 'proto-contexts' at the individual, team and cultural levels. In Chapter 8, 'The search for pana- 
ceas in Strategic Human Resource Management: a wrong turn for HRM research?', Paul Boselie and Chris Brewster discuss the universality of something that more or less has become an academic subject of its own, human resource management (HRM), and, specifically, a version of it called strategic human resource management.

\section{Part III: Contextualization by Various Groups of Actors}

Part III of the book is the 'heart' and main part of the book. The chapters deal, directly or indirectly, with how and by which groups of actors management ideas and panaceas can be examined more wisely in order to advise on whether or not they need to be adapted to fit organizations in various contexts, and how and by which actors such adaptation could best be conducted. Three sections focus each on one group of actors that is or should be involved in this process: researchers, organizational actors and lecturers/students. But Part III starts off with a chapter with valuable insights for anyone interested in critical examination of the relevance of management ideas and panaceas for organizations in certain contexts. Without addressing any particular group of actors, Östen Ohlsson and Björn Rombach suggest, in Chapter 9, 'The art of constructive criticism', how critical thinking can be accomplished through launching counter-images and saying the opposite.

In Section A, the authors deal with how researchers can be involved more fruitfully in the relevance-testing and adaptation processes. Chapter 10, 'Changing the story: management panaceas as narrative interventions', is authored by Susan Rosina Whittle, who offers recommendations for researchers as to how to add to the existing knowledge on how to contextualize management panaceas. Whittle bases her recommendations on a problematization of organizational actors' responses to the pressure to adopt management panaceas, and on a frame of reference on panaceas as ideology and panaceas as methodology (as well as methodology for handling panaceas). She also comments and reflects on the oft-cited and seminal paper she co-authored, 'Management by panacea: accounting for transience' (Gill and Whittle 1993). In Chapter 11, 'Researcher intervention in the process of contextualizing fashionable management ideas: some previous experiences', Anders Örtenblad shares his experiences from editing several books in which contributors from all over the world examine the relevance of various management ideas for organizations in various generalized contexts, and in which the management ideas, in some cases, are adapted to better fit organizations in the particular generalized context. In Chapter 12, 'A stakeholder approach to advising on the relevance of management ideas and panaceas', Anders Örtenblad, Shih-wei Hsu and Peter Lamb argue that the values that lie underneath 
any relevance-testing of management ideas and panaceas should be openly reported, and suggest how researchers could contribute by offering multistakeholder influenced examinations of management ideas and panaceas.

Section B deals with organizational actors. The first three chapters in the section are mainly descriptive and aim at increasing the understanding of relevance-testing and adaptation processes. They serve as a helpful background to the two more normatively oriented chapters appearing at the end of the section. Timothy Clark, Pojanath Bhatanacharoen and David Greatbatch offer, in Chapter 13, 'Conveying the adaptation of management panaceas: the case of management gurus', an analysis of the opportunities for adaptation of management panaceas that are given in presentations of these by management gurus, who are one important source from which organizational actors get to hear and learn about management panaceas. In Chapter 14, 'Neutralizing managerial panaceas: how universities cope with management fads', Peter Maassen and Bjørn Stensaker identify five strategies for neutralizing management panaceas used in universities, strategies which they argue hint at limitations of universal management panaceas. Based on empirical studies of CSR adoption in German companies, Stephan Bohn, Anne Galander and Peter Walgenbach develop, in Chapter 15, 'The creativity of organizations in taking corporate social responsibility: handling conflicting institutional demands', a model of the organizational implementation and handling of conflicting institutional demands, a model that aims to help us better to understand adaptation processes in organizations.

The part of Section B in which there is also a normative dimension to the chapters starts with Chapter 16, 'Excellence and intelligence: managing practice adaptation in organizations and fields', authored by Shaz Ansari, Patrick Reinmoeller and Juliane Reinecke. The authors identify three strategies through which adaptation is used in and between organizations to promote further adoption, diffusion and persistence of management panaceas (or 'practices' as the authors call them): creating variations in the practice, fostering extensiveness, and projecting impressions. Chapter 17, 'When a managerial panacea was translated rationally: the case of corporatization in the Swedish state-owned mail enterprise', is authored by Carina Abrahamson Löfström. On the basis of an empirical study of the adoption of 'corporatization' in the Swedish state-owned mail enterprise, Abrahamson Löfström offers some valuable recommendations as to how mainly organizational actors, but also facilitators, could examine, contextualize and adapt management panaceas more wisely. One of these recommendations has to do with the importance of understanding the various subcultures of the organization. In Chapter 18, 'Artistic interventions in organizations: beyond the fad', Ariane Berthoin Antal examines the trend towards bring- 
ing artists into organizations to stimulate learning processes by revealing and challenging the cultural assumptions and routines that insiders take for granted in their context. She draws on multi-stakeholder research to highlight the advantages and drawbacks of such outsiders intervening in organizations, and addresses the management roles and responsibilities in contextualizing the practice. Chapter 19, 'Good reading makes good action: nothing so practical as a managerial panacea?', by Carmelo Mazza and Jesper Strandgaard Pedersen, contributes with a perspective of managers as active producers of management panaceas, a perspective on which basis the authors examine where management ideas come from and how managers contextualize and use management panaceas. The chapter also makes a good bridge to the remainder of the book. Mazza and Strandgaard Pedersen argue both that increased attention should be given to contextualization and translation of management knowledge in management education, which is taken up in Section C, and for a sensemaking perspective of managers' adaptation of panaceas, which is taken up in Part IV of the book.

Section $\mathrm{C}$ deals with higher education, in terms of lecturers and students. In the first chapter of this section, Chapter 20, 'Smuggling panaceas by management gurus: a critical approach', Michał Zawadzki suggests what higher education would need to be like in order to educate engaged, thoughtful citizens in general, and managers equipped to put up critical resistance to dangers and traps connected with panaceas in particular. In Chapter 21, 'Empowering students to translate management panaceas', Anders Örtenblad, Peter Lamb and Shih-wei Hsu outline what a process involving students who translate management panaceas would be like. They argue that for several reasons it is urgent to teach students how to translate management panaceas, to avoid a situation where only researchers are capable performing it.

\section{Part IV: Comments and Reflections}

Part IV of the book contains chapters that comment on previous chapters of the book and/or on other issues related to the overall book theme. This part begins with a couple of chapters that mainly support the overall aim of the book, that is, the claim that management ideas and panaceas should be neither accepted outright nor rejected outright. Both authors discuss 'fashion' as a perspective on management ideas and argue, directly or indirectly, that there is reason to question the way scholars sometimes ridicule management fashions/panaceas. In Chapter 22, 'Management reforms as fashion? Critical remarks from a philosophy of science perspective', Hans Petter Saxi critically examines the 'fashion perspective' of management ideas, and argues that the perspective lacks 
a focus on actors, does not allow for practice, and lacks reality orientation. In Chapter 23, 'Theory as fashion: what are management ideas for?', Martin Parker argues that management ideas and panaceas unfairly have a somewhat bad reputation and that no part of the social world - inclusive of social research and, thus, researchers - can be outside fashion.

Every good academic book should contain at least one 'counterimage' (Ohlsson and Rombach, Chapter 9 in this volume) to its main thesis. Therefore, in Part IV there are a couple of chapters that at least to some extent can be regarded as standing in opposition to the main assumptions of the present book. In Chapter 24, 'Managerial panaceas, sensemaking, and identity construction in contemporary organizations', Charles-Clemens Rüling suggests a 'sensemaking' perspective on dealing with management panaceas, and outlines implications from adopting such a perspective. While Rüling shares the interest in actors' interpretations with the main theme of the book, his suggested perspective contradicts, at least partly, the present book in that he questions the possibility of reaching the level of rationality in adoption processes that the main part of this book prescribes, and also questions the possibility of devising contingency rules to guide organizational actors' adaptation. Building on two cases, of which one is about a very wise, brave and generous Pakistani girl and the other is a highly innovative and effective global initiative ('Uniterra'), as well as on unique philosophical perspectives and wisdom from many world traditions, Nancy J. Adler argues that we should draw on the wisdom of local people in addition to bringing in solutions from outside, in Chapter 25, 'Global wisdom: not a panacea, but absolutely necessary for transcending managerial failures'.

In the final chapter of the book, Chapter 26, 'Towards a normative theory of contextualizing management ideas and panaceas', Anders Örtenblad offers some general conclusions on how more wisely to adapt and contextualize management panaceas that can be drawn on the basis of the previous chapters, and also offers some suggestions for further research.

\section{NOTES}

1. For various reasons, many of the contributors to the present book deal with both instrumental and symbolic use in their chapters. One reason is that it is difficult, on an empirical level, to tell these two kinds of use apart.

2. 'Balancing between adopting, abandoning and adapting' is sometimes termed the $2 \mathrm{~B} 3 \mathrm{~A}$ rule (or the 2Beta3Alfa rule). 


\section{REFERENCES}

Abrahamson, E. (1991), 'Managerial fads and fashions: the diffusion and rejection of innovations', Academy of Management Review, 16 (3), 586-612.

Abrahamson, E. (1996), 'Management fashion', Academy of Management Review, 21 (1), 254-85.

Abrahamson, E. and M. Eisenman (2001), 'Why management scholars must intervene strategically in the management knowledge market', Human Relations, 54 (1), 67-75.

Abrahamson Löfström, Carina (2013), 'The learning organization in elderly care: can it fit?', in Anders Örtenblad (ed.), Handbook of Research on the Learning Organization: Adaptation and Context, Cheltenham, UK, and Northampton, MA, USA: Edward Elgar Publishing, pp. 196-209.

Ahmad, Aini (2013), 'Islamic perspective of the learning organization', in Anders Örtenblad (ed.), Handbook of Research on the Learning Organization: Adaptation and Context, Cheltenham, UK, and Northampton, MA, USA: Edward Elgar Publishing, pp. 145-56.

Alvarez, José L. (1998), 'The sociological tradition and the spread and institutionalization of knowledge for action', in José L. Alvarez (ed.), The Diffusion and Consumption of Business Knowledge, London: Macmillan, pp. 13-57.

Andersson, T. (2008), 'Personal growth and sensitivity training as fashions in management and management research', International Studies of Management \& Organization, 38 (2), 71-96.

Astley, W.G. and R.F. Zammuto (1992), 'Organization science, managers and language games', Organization Science, 3 (4), 443-60.

Bamberger, P. (2008), 'From the editors. Beyond contextualization: using context theories to narrow the micro-macro gap in management research', Academy of Management Journal, $51(5), 839-46$.

Bartunek, J.M. and G.M. Spreitzer (2006), 'The interdisciplinary career of a popular construct used in management: empowerment in the late 20th century', Journal of Management Inquiry, 15 (3), 255-73.

Benders, J. and K. van Veen (2001), 'What's in a fashion? Interpretative viability and management fashions', Organization, 8 (1), 33-53.

Benders, J. and S. Verlaar (2003), 'Lifting parts: putting conceptual insights into practice', International Journal of Operations \& Production Management, 23 (7), 757-74.

Birkinshaw, J., G. Hamel and M.J. Mol (2008), 'Management innovation', Academy of Management Review, 33 (4), 825-45.

Blackman, Deborah A. (2013), 'Contextualizing the learning organization: how will it help us learn in the future?', in Anders Örtenblad (ed.), Handbook of Research on the Learning Organization: Adaptation and Context, Cheltenham, UK and Northampton, MA, USA: Edward Elgar Publishing, pp. 372-83.

Bort, S. and A. Kieser (2011), 'Fashion in organization theory: an empirical analysis of the diffusion of theoretical concepts', Organization Studies, 32 (5), 655-81.

Boxenbaum, E. (2006), 'Lost in translation: the making of Danish diversity management', The American Behavioral Scientist, 49 (7), 939-48.

Boyacigiller, N.A. and N.J. Adler (1991), 'The parochial dinosaur: organizational science in a global context', Academy of Management Review, 16 (2), 262-90.

Bruning, N.S. and R.L. Tung (2013), 'Editorial. Leadership development and global talent management in the Asian context: an introduction', Asian Business \& Management, 12 (4), 381-6.

Callon, Michel (1986), 'Some elements of a sociology of translation: domestication of the scallops and the fishermen of St Brieuc Bay', in John Law (ed.), Power, Action and Belief: A New Sociology of Knowledge, London: Routledge \& Kegan Paul, pp. 196-233.

Christensen, T. and P. Lægreid (2003), 'Administrative reform policy: the challenges of turning symbols into practice', Public Organization Review, 3 (1), 3-27.

Collins, David (2000), Management Fads and Buzzwords: Critical-Practical Perspectives, London: Routledge. 
Czarniawska, Barbara and Bernward Joerges (1996), 'Travels of ideas', in Barbara Czarniawska and Guje Sevón (eds), Translating Organizational Change, Berlin: de Gruyter, pp. 13-48.

Czarniawska, Barbara and Guje Sevón (eds) (1996), Translating Organizational Change, Berlin: de Gruyter.

Davis, M.S. (1986), “That's classic!”: the phenomenology and rhetoric of successful social theories', Philosophy of the Social Sciences, 16 (3), 285-301.

Delgado-Hernández, David J. (2014), 'Knowledge management case studies in Mexico', in Anders Örtenblad (ed.), Handbook of Research on Knowledge Management: Adaptation and Context, Cheltenham, UK and Northampton, MA, USA: Edward Elgar Publishing, pp. $268-93$.

Doorewaard, H. and M. van Bijsterveld (2001), 'The osmosis of ideas: an analysis of the integrated approach to IT management from a translation theory perspective', Organization, $8(1), 55-76$.

Driver, M. (2002), 'The learning organization: Foucauldian gloom or utopian sunshine?', Human Relations, 55 (1), 33-53.

Eccles, Robert G. and Nitin Nohria (1992), Beyond the Hype: Rediscovering the Essence of Management, Cambridge, MA: Harvard Business School Press.

Edwards, John S. (2014), 'Knowledge management in energy sector organizations', in Anders Örtenblad (ed.), Handbook of Research on Knowledge Management: Adaptation and Context, Cheltenham, UK and Northampton, MA, USA: Edward Elgar Publishing, pp. $157-72$.

Fey, C.F. and D.R. Denison (2003), 'Organizational culture and effectiveness: can American theory be applied in Russia?', Organization Science, 14 (6), 686-706.

Fiedler, Fred E. (1978), 'The contingency model and the dynamics of the leadership process', in Leonard Berkowitz (ed.), Advances in Experimental Social Psychology, vol. 11, pp. 59-112.

Fink, D. (2003), 'A life cycle approach to management fashion: an investigation of management concepts in the context of competitive strategy', Schmalenbach Business Review, 55 (1), 46-59.

Fiss, P.C., M.T. Kennedy and G.F. Davis (2012), 'How golden parachutes unfolded: diffusion and variation of a controversial practice', Organization Science, 23 (4), 1077-99.

Frenkel, M. (2005), 'The politics of translation: how state-level political relations affect the cross-national travel of management ideas', Organization, 12 (2), 275-301.

Gibson, J.W. and D.V. Tesone (2001), 'Management fads: emergence, evolution, and implications for managers', Academy of Management Perspectives, 15 (4), 122-33.

Gill, J. and S. Whittle (1993), 'Management by panacea: accounting for transience', Journal of Management Studies, 30 (2), 281-95.

Giroux, H. (2006), "It was such a handy term": management fashions and pragmatic ambiguity', Journal of Management Studies, 43 (6), 1227-60.

Gond, J-P. and E. Boxenbaum (2013), 'The glocalization of responsible investment: contextualization work in France and Québec', Journal of Business Ethics, 115 (4), 707-21.

Hamisi, S. (2011), 'Challenges and opportunities of Tanzanian SMEs in adapting supply chain management', African Journal of Business Management, 5 (4), 1266-76.

Heiskanen, E., S. Kivisaari, R. Lovio and P. Mickwitz (2009), 'Designed to travel? Transition management encounters environmental and innovation policy histories in Finland', Policy Sciences, 42 (4), 409-27.

Hofstede, G. (1996), 'An American in Paris: the influence of nationality on organization theories', Organization Studies, 17 (3), 525-37.

Huczynski, Andrzej A. (1993 [1996]), Management Gurus: What Makes Them and How to Become One, London: Thomson.

Jamali, Dima and Charlotte Karam (forthcoming), 'CSR in developed versus developing countries: a comparative glimpse', in Anders Ortenblad (ed.), Research Handbook on Corporate Social Responsibility in Context, Cheltenham, UK and Northampton, MA, USA: Edward Elgar Publishing. 
Johns, G. (2001), 'In praise of context', Journal of Organizational Behavior, 22 (1), 31-42.

Johns, G. (2006), 'The essential impact of context on organizational behavior', Academy of Management Review, 31 (2), 386-408.

Kelemen, M. (2000), 'Too much or too little ambiguity: the language of total quality management', Journal of Management Studies, 37 (4), 483-98.

Kieser, A. (1997), 'Rhetoric and myth in management fashion', Organization, 4 (1), 49-74.

Kinder, T. (2002), 'Are schools learning organisations?', Technovation, 22 (6), 385-404.

Latour, Bruno (1986), 'The powers of association', in John Law (ed.), Power, Action and Belief: A New Sociology of Knowledge?, London: Routledge \& Kegan Paul, pp. 264-80.

Latour, Bruno (1987), Science in Action, Cambridge, MA: Harvard University Press.

Lekakou, Maria, Ioannis Theotokas and Evangelia Stefanidaki (forthcoming), 'Corporate social responsibility in the shipping industry', in Anders Örtenblad (ed.), Research Handbook on Corporate Social Responsibility in Context, Cheltenham, UK and Northampton, MA, USA: Edward Elgar Publishing.

Lervik, J.E., B.W. Hennestad, R.P. Amdam, R. Lunnan and S.M. Nilsen (2005), 'Implementing human resource development best practices: replication or re-creation?', Human Resource Development International, 8 (3), 345-60.

Love, E.G. and P. Cebon (2008), 'Meanings on multiple levels: the influence of field-level and organizational-level meaning systems on diffusion', Journal of Management Studies, 45 (2), 239-67.

Lwoga, Edda T., Christine Stilwell and Patrick Ngulube (2014), 'Knowledge management and indigenous organizations with special reference to Tanzania and South Africa', in Anders Örtenblad (ed.), Handbook of Research on Knowledge Management: Adaptation and Context, Cheltenham, UK and Northampton, MA, USA: Edward Elgar Publishing, pp. 318-40.

Mamman, A. (2002), 'The adoption and modification of management ideas in organizations: towards an analytical framework', Strategic Change, 11 (7), 341-89.

McDowell, Denise, Anita Rynne and Steven Talbot (2014), 'The Australian Army's knowledge management strategy: a reflexive organizational approach to knowledge capture and sharing', in Anders Örtenblad (ed.), Handbook of Research on Knowledge Management: Adaptation and Context, Cheltenham, UK and Northampton, MA, USA: Edward Elgar Publishing, pp. 87-110.

McKinley, W. (1996), 'What's hot and what's not', Academy of Management Review, 21 (3), 614-16.

Meyer, J.W. and B. Rowan (1977), 'Institutionalized organizations: formal structure as myth and ceremony', American Journal of Sociology, 83 (2), 340-63.

Mintzberg, H. (1981), 'Organization design: fashion or fit?', Harvard Business Review, 59 (1), 103-16.

Mintzberg, Henry (1983), Structure in Fives: Designing Effective Organizations, Englewood Cliffs, NJ: Prentice-Hall.

Mitra, Amit and Ximing Ruan (2014), 'Knowledge management in China's organizations', in Anders Örtenblad (ed.), Handbook of Research on Knowledge Management: Adaptation and Context, Cheltenham, UK and Northampton, MA, USA: Edward Elgar Publishing, pp. $294-317$.

Morris, T. and Z. Lancaster (2006), 'Translating management ideas', Organization Studies, 27 (2), 207-33.

Nicolai, A.T. and H. Röbken (2005), 'Scientification, immune responses, and reflection: the changing relationship between management studies and consulting', Journal of Organizational Change Management, 18 (5), 416-35.

Örtenblad, A. (1999), "The fashionable fashion concept" or "researchers have their fashions too", paper presented at the EGOS 15th Colloquium, Warwick University, UK.

Örtenblad, A. (2007), 'Senge's many faces: problem or opportunity?', The Learning Organization, 14 (2), 108-22.

Örtenblad, Anders (2013), 'Introduction. Putting the learning organization into context: an emerging research field', in Anders Örtenblad (ed.), Handbook of Research on the Learning 
Organization: Adaptation and Context, Cheltenham, UK and Northampton, MA, USA: Edward Elgar Publishing, pp. 3-21.

Örtenblad, A. and R. Koris (2014), 'Is the learning organization idea relevant to higher educational institutions? A literature review and a "multi-stakeholder contingency approach", International Journal of Educational Management, 28 (2), 173-214.

Pelz, Donald C. (1978), 'Some expanded perspectives on use of social science in public policy', in John M. Yinger and Stephen J. Cutler (eds), Major Social Issues: A Multidisciplinary View, New York: Free Press, pp. 346-57.

Perkmann, M. and A. Spicer (2008), 'How are management fashions institutionalized? The role of institutional work', Human Relations, 61 (6), 811-44.

Risberg, A. and A-M. Søderberg (2008), 'Translating a management concept: diversity management in Denmark', Gender in Management: An International Journal, 23 (6), 426-41.

Rousseau, D.M. and Y. Fried (2001), 'Editorial. Location, location, location: contextualizing organizational research', Journal of Organizational Behavior, 22 (1), 1-13.

Røvik, Kjell Arne (1996), 'Deinstitutionalization and the logic of fashion', in Barbara Czarniawska and Guje Sevón (eds), Translating Organizational Change, Berlin: de Gruyter, pp. 139-72.

Røvik, K.A. (1998), 'The translation of popular management ideas: towards a theory', paper presented at the EGOS 14th Colloquium, Maastricht University, the Netherlands, 9-11 July.

Røvik, Kjell Arne (2002), 'The secrets of the winners: management ideas that flow', in Kerstin Sahlin-Andersson and Lars Engwall (eds), The Expansion of Management Knowledge: Carriers, Flows and Sources, Stanford, CA: Stanford University Press, pp. 113-44.

Røvik, K.A. (2011), 'From fashion to virus: an alternative theory of organizations' handling of management ideas', Organization Studies, 32 (5), 631-53.

Ryan, S. and J. Hurley (2004), 'Have total quality management, business process reengineering and the learning organization been replaced by knowledge management?', Irish Journal of Management, 25 (1), 41-55.

Scarbrough, H. and J. Swan (2001), 'Explaining the diffusion of knowledge management: the role of fashion', British Journal of Management, 12 (1), 3-12.

Sorge, A. and A. van Witteloostuijn (2004), 'The (non)sense of organizational change: an essay about universal management hypes, sick consultancy metaphors, and healthy organization theories', Organization Studies, 25 (7), 1205-31.

Starbuck, W.H. (2009), 'The constant causes of never-ending faddishness in the behavioral and social sciences', Scandinavian Journal of Management, 25 (1), 108-16.

Stensaker, Bjørn (2007), 'Quality as fashion: exploring the translation of a management idea into higher education', in Don F. Westerheijden, Bjørn Stensaker and Maria João Rosa (eds), Quality Assurance in Higher Education: Trends in Regulation, Translation and Transformation, Dordrecht: Springer, pp.99-118.

Sturdy, A. (2004), 'The adoption of management ideas and practices: theoretical perspectives and possibilities', Management Learning, 35 (2), 155-80.

Tsui, A.S. (2007), 'From homogenization to pluralism: international management research in the academy and beyond', Academy of Management Journal, 50 (6), 1353-64.

Wæraas, A. and H.L. Sataøen (2014), 'Trapped in conformity? Translating reputation management into practice', Scandinavian Journal of Management, 30 (2), 242-53.

Watkins, K.E. (2005), 'What would be different if higher educational institutions were learning organizations?', Advances in Developing Human Resources, 7 (3), 414-21.

Watson, T.J. (1994), 'Management "flavours of the month": their role in managers' lives', International Journal of Human Resource Management, 5 (4), 893-909.

Whetten, D.A. (2009), 'An examination of the interface between context and theory applied to the study of Chinese organizations', Management and Organization Review, 5(1), 29-55.

Zeitz, G., V. Mittal and B. McAulay (1999), 'Distinguishing adoption and entrenchment of management practices: a framework for analysis', Organization Studies, 20 (5), 741-76. 